\title{
Price discovery of credit spreads in tranquil and crisis periods
}

Article

Accepted Version

Avino, D., Lazar, E. and Varotto, S. (2013) Price discovery of credit spreads in tranquil and crisis periods. International Review of Financial Analysis, 30. pp. 242-253. ISSN 10575219 doi: https://doi.org/10.1016/j.irfa.2013.08.002 Available at https://centaur.reading.ac.uk/33620/

It is advisable to refer to the publisher's version if you intend to cite from the work. See Guidance on citing.

To link to this article DOI: http://dx.doi.org/10.1016/j.irfa.2013.08.002

Publisher: Elsevier

All outputs in CentAUR are protected by Intellectual Property Rights law, including copyright law. Copyright and IPR is retained by the creators or other copyright holders. Terms and conditions for use of this material are defined in the End User Agreement.

\section{www.reading.ac.uk/centaur}

\section{CentAUR}

Central Archive at the University of Reading

Reading's research outputs online 


\section{Accepted Manuscript}

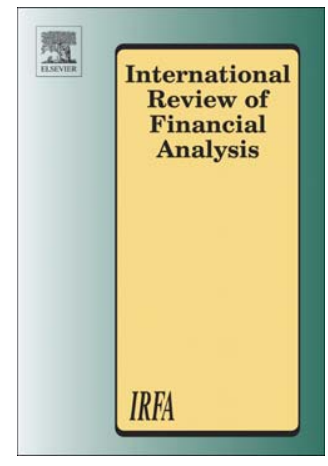

DOI: doi: $10.1016 /$ j.irfa.2013.08.002

Reference: $\quad$ FINANA 628

To appear in: $\quad$ International Review of Financial Analysis

Received date: 1 November 2012

Revised date: $\quad 26$ July 2013

Accepted date: 6 August 2013

Please cite this article as: Avino, D., Lazar, E. \& Varotto, S., Price discovery of credit spreads in tranquil and crisis periods, International Review of Financial Analysis (2013), doi: $10.1016 /$ j.irfa.2013.08.002

This is a PDF file of an unedited manuscript that has been accepted for publication. As a service to our customers we are providing this early version of the manuscript. The manuscript will undergo copyediting, typesetting, and review of the resulting proof before it is published in its final form. Please note that during the production process errors may be discovered which could affect the content, and all legal disclaimers that apply to the journal pertain. 


\title{
Price discovery of credit spreads in tranquil and crisis periods*
}

\author{
Davide Avino $^{\mathrm{a}}$, Emese Lazar ${ }^{\mathrm{b}}$, Simone Varotto ${ }^{\mathrm{b}}$
}

Current version: July 2013

\begin{abstract}
In this paper we investigate the price discovery process in single-name credit spreads obtained from bond, credit default swap (CDS), equity and equity option prices. We analyse short term price discovery by modelling daily changes in credit spreads in the four markets with a vector autoregressive model (VAR). We also look at price discovery in the long run with a vector error correction model (VECM). We find that in the short term the option market clearly leads the other markets in the sub-prime crisis (2007-2009). During the less severe sovereign debt crisis (2009-2012) and the pre-crisis period, options are still important but CDSs become more prominent. In the long run, deviations from the equilibrium relationship with the option market still lead to adjustments in the credit spreads observed or implied from other markets. However, options no longer dominate price discovery in any of the periods considered. Our findings have implications for traders, credit risk managers and financial regulators.
\end{abstract}

JEL classification: G01; G12; G14; G20; D8

Keywords: credit spreads; price discovery; CDS; information flow

\footnotetext{
* Davide Avino acknowledges partial financial support from Science Foundation Ireland (08/SRC/FMC1389). We thank Carol Alexander, Chris Brooks, Chris Finger, Robert Stamicar, Satchit Sagade, Madhucchand Darbha, two anonymous referees and seminar/conference participants at the CREDIT 2011 Conference, IRMC 2012 Conference, Eastern Finance Association 2013 and ICMA Centre for their helpful comments and suggestions. Contact: davide.avino@ucd.ie (D. Avino), e.lazar@icmacentre.ac.uk (E. Lazar) and s.varotto@icmacentre.ac.uk (S. Varotto).

a Department of Banking and Finance, Smurfit Graduate School of Business, University College Dublin, Carysfort Avenue, Blackrock, Dublin, Ireland (Corresponding author).

b ICMA Centre, Henley Business School, University of Reading, Reading, RG6 6BA, United Kingdom.
} 


\section{Introduction}

An extensive literature shows the impact of credit risk on bond prices (early contributions in this area are Fisher, 1959, Johnson, 1967, Merton, 1974 and Sarig and Warga, 1989, among others) and recent research has started to single out and analyse a credit risk factor in stock prices (Dichev, 1998, Vassalou and Xing, 2004, Chava and Purnanandam, 2010). The important role of credit risk in securities prices has also led bank regulators to introduce new capital requirements that reflect the potential for credit risk related losses in traded instruments. ${ }^{1}$ In the light of recent events, it is important for financial economists, traders and regulators to identify the markets that incorporate credit risk related information most quickly and lead other markets in the price discovery process. Such information may give an early warning on imminent and possible large shocks in asset prices. $^{2}$ In addition, an understanding of the transmission mechanism of credit risk information across markets and its evolution over time may shed light on the relative efficiency of the markets and on the way their role changes in different market conditions. In this paper we investigate the discovery of the price of credit risk in the bond, CDS, stock and option markets over the period 2006-2012.

The credit risk associated with a company may be measured in the credit market, via the credit spread of bonds issued by that company and via the price of CDSs written on those bonds. Indirectly, credit risk can also be quantified through implied credit spreads. Based on Merton (1974), Kealhofer (2003a and b) and Vassalou and Xing (2004) show how information on credit risk can be extracted from equity prices. Hull et al. (2005), Stamicar and Finger (2006) and Cao et al. (2011), on the other hand, show how to use the price of options written on a firm's stock to obtain implied credit spreads.

Several papers look at price discovery in the bond and CDS markets (e.g. Blanco et al., 2005 and Zhu, 2006) and bond, CDS and stock markets (Longstaff et al., 2003, Norden and Weber, 2009 and Forte and Peña, 2009). However, the role of the option market in the price discovery of credit risk has attracted less attention. Recent research has found that the implied volatility of options written on stocks or stock futures can help explain credit spreads (Collin-Dufresne et al., 2001, Cremers et al., 2008, Berndt and Ostrovnaya, 2008, Cao et al., 2010 and Alexander and Kaeck, 2008). This is not surprising as banks and hedge funds routinely implement arbitrage trading strategies that are based on the discrepancies between the credit spreads implied from equity options and the spreads of bonds and

\footnotetext{
${ }^{1}$ In order to cope with increased migration risk, default clustering and loss of liquidity in crisis periods (which may negatively affect corporate bond prices as well as equity prices, among other securities), bank regulators have introduced an additional capital requirement for trading securities, namely the Incremental Risk Charge (IRC), which is based on a 1-year risk horizon and a $99.9 \%$ confidence level for Value-at-Risk estimations, similarly to the capital requirements on non-trading bank loans (Basel Committee on Banking Supervision, 2009)

${ }^{2}$ For example, Hamalainen et al. (2012) show how the market prices of credit default swaps (CDS), subordinated debt and equities and the implied volatility from option prices were useful early warning indicators of the financial problems at Northern Rock, which was eventually bailed out in September 2007.
} 
CDS contracts for individual firms as shown in JPMorgan (2006) and Kapadia and Pu (2012). ${ }^{3}$ In particular, Kapadia and $\mathrm{Pu}$ (2012) find that equity and credit markets co-move and are fairly integrated over the long run. This suggests that, from the point of view of our analysis, they are both expected to have a significant role in the price discovery of credit risk. However, they also show that, in the short run, pricing discrepancies between equity and credit markets may persist because of constraints to arbitrage (such as liquidity and idiosyncratic risk). The implication is that an analysis of price discovery in the short run and long run may lead to different results.

Based on previous findings, we expect CDS, bond, equity and option spreads to contribute to the price discovery of credit risk, and their informative role to be dependent on various factors related to the trading conditions that characterize each market. To the extent that information is incorporated into securities' prices through trading activity, a strong link should exist between price discovery and trading-related variables such as trading volumes, bid-ask spreads and volatility. We would expect this pattern to differ in the pre-crisis and crisis periods, due to the effect the crisis had on the previously mentioned trading-specific variables. Chakravarty et al. (2004) investigate the price discovery in stock and option prices and find that price discovery is associated with high trading volume and narrow bid-ask spreads. Given our lack of data on trading volumes and transaction prices for all securities under analysis, we are unable to investigate the changing nature of trading activity in each market (which determines the changing patterns of price discovery documented in our work). We then limit our study to an investigation of the important empirical question of which market most timely incorporates credit-related information.

We add to the existing literature by (1) analysing, for the first time, all the markets that may contribute to the price discovery of credit risk, namely the bond, CDS, equity and option markets; (2) performing our analysis over an extended sample period including the 2007-2009 sub-prime crisis and the 2009-2012 sovereign debt crisis, which allows us to investigate changes in price discovery under different market conditions. We find that when we employ a vector autoregressive model (VAR) on daily credit spread changes to look at the price discovery in the short term, the option market clearly leads the others in the sub-prime crisis, that is the period of highest uncertainty in our sample (see Figure 1). However, during the less severe sovereign debt crisis (2009-2012) and the pre-crisis period, though options are still important, CDSs become the most prominent market. Interestingly, when we use a vector error correction specification (VECM) and consider how credit spreads adjusts to deviations from long run equilibrium relationships, options still influence other markets but no longer have a prominent role regardless of market conditions. We conclude that during periods of pronounced market dislocation, credit spreads react to shocks first registered in the option market but also to deviations from long term trends that are better captured in the other markets. Specifically, the

\footnotetext{
${ }^{3}$ These strategies do not ensure riskless profits as the traditional meaning of arbitrage implies, hence they are referred to as "risky arbitrage".
} 
CDS and equity markets lead the long run price discovery of credit spreads during both the pre-crisis period and the sovereign crisis period. However, the bond market becomes more influential in the sub-prime crisis and especially for the European sample of firms, where it appears to be the leading market. In our US sample, the CDS market leads long run price discovery during the sub-prime crisis.

Our findings should be of interest to various market participants. Policymakers, concerned about the stability of the whole financial system, should benefit from a better understanding of how equities, bonds, options and credit derivatives are interlinked during periods of high and low volatility. Also, understanding which market contributes the most to price discovery becomes crucial to provide timely responses to systemic crises. Hedgers and arbitrageurs are also clearly interested in receiving the earliest possible signals of credit risk reversals.

The remainder of the paper is organised as follows: Section 2 reviews the related literature on credit risk price discovery. Sections 3 and 4 describe the data and our methodology. In Section 5 and 6 we discuss the main results and robustness tests. Section 7 concludes.

\section{Literature review}

The literature on price discovery in credit spreads is relatively recent. Zhu (2006) analyses CDS and bond spreads and finds that CDSs lead price discovery in the US market. Another study on the relationship between the bond and CDS markets in Europe and the US is that of Blanco et al. (2005), concluding that the CDS market is responsible, on average, for about 80 percent of price discovery over their sample period. Das et al. (2012) show that the introduction of CDS trading undermines the efficiency and liquidity of the underlying corporate bond market. Bai and Collin-Dufresne (2011) find that price discovery in the CDS market decreased during the financial crisis of 2008 in favour of the bond market for a sample of US companies. Acharya and Johnson (2007) and Hilscher et al. (2013) study the information flow between CDS and equity markets for US individual obligors. The former find evidence of insider trading in the CDS market during the 2001-2004 period, arguing that this could be a reason for the leading price discovery role of the CDS market against the equity market. However, this informational advantage is found only in the presence of negative credit news.

HERE

On the other hand, the latter study finds that equity returns predict CDS returns for a larger sample of firms over the period 2001-2007. Elkamhi et al. (2012) investigate how quickly earning announcements, changes in analyst recommendation and management guidance are incorporated into CDS spreads. Using logistic regressions, they find strong evidence that accounting information is 
priced into CDS spreads on the day of the announcement, which suggests that the CDS market is characterized by an efficient price discovery process.

Longstaff et al. (2003) are the first to jointly analyse the lead-lag relations between bonds, CDSs as well as stocks. They find that the CDS and equity markets lead the bond market most of the time. However, based on a study using a VAR, Norden and Weber (2009) find that the stock market is more likely to lead the other two markets and the CDS market appears to lead the bond market. The leading role of the CDS market on the bond market is also confirmed by the same authors with a bivariate VECM specification. The first study to analyse the three markets (CDS, bonds and equities) in a VECM framework is that of Forte and Peña (2009). They perform a price discovery analysis that is intuitively more appealing than in previous contributions as they compare homogeneous measures of credit risk in terms of observed or implied credit spreads obtained from the three markets. Their main finding is consistent with Norden and Weber (2009) in the sense that the stock market leads the price discovery process, followed by the CDS market.

Early insights into the relevance of the option market (using option implied volatilities as determining factors of credit spreads) are given in the seminal paper of Collin-Dufresne et al. (2001). Their study finds that changes in the slope of the "smirk" of implied volatilities of options on S\&P500 futures is a statistically significant explanatory variable for the changes in bond credit spreads. Results for individual companies were obtained by Cao et al. (2010) who find that the option-implied volatility of individual companies is important to explain single-name CDS spreads and its significance increases for companies characterised by high volatility in CDS spreads, low credit rating and large option trading volume. Similar results are found by Cremers et al. (2008), who confirm the importance of option-implied volatilities in explaining levels of bond credit spreads. They also find that the volatility skew of individual companies is significant, in line with the results of Collin-Dufresne et al. (2001). Another interesting study on the significance of the option market is that of Alexander and Kaeck (2008), who use Markov switching regressions to explain changes in European CDS indices in different regimes. Their main conclusion is that option-implied volatilities represent the main determinant of changes in CDS spreads in a volatile regime, whereas in stable conditions equity market returns have a predominant role.

Lastly, Berndt and Ostrovnaya (2008) study how negative news is built into option prices, CDS spreads and stock prices. Following Acharya and Johnson (2007) they use predictive regression coefficients to the information flow across markets. They conclude that the flow of information in the CDS and option market works both ways. But, prior to some adverse market news, such as accounting scandals, the option market carries superior information. Using a similar methodology, Cao et al. (2010) find that option implied volatility innovations are more capable to predict future CDS spread changes than the other way around. However, both Berndt and Ostrovnaya (2008) and Cao et al. 
(2010) do not convert the information from different markets into common and comparable credit risk measures, that is, credit spreads. Hence, they don't take into account the long run equilibrium relationship that may exist among the spreads implied from the different markets. Furthermore, they do not consider the bond market which may be an important source of information in the price discovery process.

\section{Data}

In our analysis we use daily observations of CDS mid-quotes, bond yields, equity prices and option implied volatilities for a sample of 30 US and European non-financial companies from January 2006 until December 2012. Our initial sample comprises the 300 largest US and European firms by market capitalization. Following Longstaff et al. (2003), we retain only those companies for which at least 100 observations per year are simultaneously available, on the same dates, for the securities in the four markets considered. Out of the 300 selected firms, 264 are dropped due to insufficient bond data and 6 are eliminated because of lack of equity implied volatilities. Sample size has always been a problem in the price discovery literature on credit spreads, mainly due to missing data. Our study is the first that considers four markets at the same time, which means that additional missing values may further shorten the sample of dates available for the analysis and hence restrict the number of companies with sufficient observations across all the four markets. In addition, the use of a longer sample period imposes further restrictions due to the difficulty in finding bonds with desired maturity, for each firm, for the whole observation period. ${ }^{4}$ However, our final sample of non-financial companies compares favourably with previous studies both in terms of number of firms and length of the sample period analysed. ${ }^{5}$

\section{A. CDS and Bond Data}

CDS bid and ask quotes for various maturities are obtained from Datastream, who source their data from CMA. According to Mayordomo et al. (2013), CMA data on CDS are the best available as they lead the price discovery process if compared with other popular CDS datasets such as GFI, Fenics, Markit, JP Morgan and Reuters. ${ }^{6}$ Unfortunately, CMA data from Datastream are only available until the end of September 2010. Starting from October 2010 until the end of our sample, Datastream

\footnotetext{
${ }^{4}$ In particular, for most of the companies in our sample at least four bonds have to be used to generate a synthetic 5-year spread covering the whole sample period.

${ }^{5}$ Sample sizes (number of non-financial companies) used in previous studies are: 39 in Norden and Weber (2009), 17 in Forte and Peña (2009), 18 in Blanco et al. (2005) and 16 in Zhu (2006).

${ }^{6}$ This finding is particularly important to identify the true role of CDS in the price discovery analysis of credit spreads.
} 
provides CDS quotes obtained from Thomson Reuters. ${ }^{7}$ We restrict our analysis to senior unsecured CDSs with 5 year maturity as they are the most liquid. For each of the companies, we use Bloomberg to find pairs of bonds which (1) are denominated in US dollars for US firms and Euros for European firms, (2) are senior unsecured, (3) have "generic" Bloomberg mid-market prices, that is, average quotes from at least five brokers or dealers; (4) are not floating-rate and do not have embedded options or any special features; (5) one bond has a maturity below 5 years while the other has a maturity above 5 years. $^{8}$ We then construct synthetic 5 -year credit spreads for each company by taking the difference between the synthetic 5-year yield (obtained by linear interpolation of the pair of bonds) and the corresponding risk free rate (downloaded from Bloomberg). In particular, we use the 5-year swap rates for US dollars and Euros which are regarded as the best proxy for the risk free rate (see Hull et al., 2005 and Houweling and Vorst, 2005).

\section{B. Equity and Option Data}

We employ the CreditGrades structural model to estimate the 5-year equity implied spreads. The model is widely used by both researchers and practitioners. Recent studies that have employed this model are Duarte et al. (2007) and Yu (2006). A summary of its main features is presented in the Appendix. In order to implement CreditGrades, we need the following inputs for each company: daily series of stock prices and market capitalizations; accounting data including short-term and long-term liabilities, minority interest, preferred shares; the mean global recovery rate (on each firm's debt of any seniority) $\bar{L}$ and its standard deviation $\lambda$; the recovery rate of the firm's senior unsecured debt, $R$; the annualized equity volatility $\sigma_{S}$ and the 5 -year risk-free interest rate $r$.

Stock prices, market capitalisations, accounting data and 5-year swap rates are downloaded from Bloomberg. For $\bar{L}$ and $\lambda$ we take the estimated values of 0.5 and 0.3 , respectively, reported in the CreditGrades Technical Document (2002), which are based on historical data of about 300 nonfinancial companies. The recovery rate $R$ is estimated as the Moody's average historical recovery rate on senior unsecured debt over the period 1982-2009 (see Moody's 2011) and is equal to 0.326. As a proxy for the risk-free rate, we use again the 5-year swap rates. To estimate the equity volatility $\sigma_{S}$ we follow the CreditGrades Technical Document (2002). However, while CreditGrades employs a 1,000day moving average of past equity stock returns ${ }^{9}$, we resort to a 40-day moving average to improve the volatility's responsiveness to changing market conditions. This is consistent with the shorter time

\footnotetext{
${ }^{7}$ Datastream reports Thomson Reuters CDS historical data from 2007.

${ }^{8}$ For most of the companies, we calculate 5-year spreads via linear interpolation. However, for some of them and for only a small part of the sample period, we could not find enough bonds with maturity above 5 years so we had to resort to linear extrapolation.

${ }^{9}$ Bharath and Shumway (2008) and Vassalou and Xing (2004) use a 250-day rolling window to estimate the equity returns' volatility in their implementation of the Merton model.
} 
span (2 months) used to obtain option implied volatilities for the estimation of option implied spreads, which is discussed next.

In order to estimate the 5-year option implied spreads, we use an extended version of the CreditGrades model as described in Stamicar and Finger (2006). To implement the model we only need daily implied volatilities for 2-month equity at-the-money put options which we obtain from Bloomberg.

Matching the four series of spreads for each company leaves us with a final sample of 30 firms, 11 of which are based in the US, while the remaining 19 are European. The large downsizing in the number of firms available for our study (from 300 to 30) is mostly due to lack of bond data.

In the analysis that follows we split our sample into a pre-crisis sub-sample which starts in January 2006 and ends in July 2007, a sub-prime crisis sub-sample that begins in August 2007 and lasts until the end of July 2009 and a sample including the most recent sovereign debt crisis, which goes from August 2009 and ends in December 2012. We set August 1 $1^{\text {st }}, 2007$ as the starting time of the subprime crisis because the cost of insurance against default for several companies doubled in that month. We set August $1^{\text {st }}, 2009$ as the starting time of the sovereign debt crisis because the first signs of market instability in sovereign credit spreads occurred in the second half of 2009.

Descriptive statistics of the four series of credit spreads are shown in Table 1. We report the 10\%, $50 \%, 90 \%$ quantiles, the number of observations and the standard deviation of credit spread levels. We also report these statistics by region (US and Europe) and sample periods. The most evident difference across median values is the large discrepancy between bond and CDS spreads on one side and equity and option implied spreads on the other. This is further confirmation of the well-known "credit spread puzzle" that has been widely documented in the literature (see, for example, Jones et al., 1984, Eom et al., 2004, Huang and Huang, 2012, Ericsson et al., 2005, Collin-Dufresne et al., 2001 and Kapadia and $\mathrm{Pu}, 2012$ ) and highlights how structural credit risk models based on the work of Merton (1974) (like the ones used to generate equity and option implied spreads) tend to produce spreads far below those observed in the bond market. Although the structural models behind equity and option implied spreads may not fully explain the level of credit spreads observed in the bond and CDS markets, it is not unreasonable to expect that they may provide market participants with useful price discovery signals as shown by previous studies (see, for instance, Forte and Peña, 2009).

Table 1 also reveals that the $90 \%$ quantiles of equity and option implied spreads are larger than the corresponding ones for bonds and CDSs. Upon close inspection, we notice that the larger high quantile spreads of equity and option markets occur only during the sub-prime crisis. This may be due to the short rolling window (of 40 days) used for the estimation of the equity implied spreads. The short window enables us to obtain spreads that react promptly to changing market conditions. As a 
result, low equity implied spreads are produced in the period preceding the crisis ${ }^{10}$ and remarkably high spreads in the crisis period due to the occurrence of large negative shocks to the equity prices. The same applies to option implied spreads as they have been estimated with short maturity (2-month) equity put options. Figure 1 shows daily cross sectional median spreads obtained from the four markets. We can clearly see how the sub-prime crisis period is characterised by the highest volatility in the four markets.

In order to get a first grasp of the interactions across the four markets, Table 2 reports the pairwise contemporaneous correlations of daily credit spread changes. In general, as one would expect, they are always positive except in one case. If we focus on the whole sample period, they are in the range of 0.03 (between CDS and option implied spreads) and 0.17 (for the correlation of CDS and bond spreads), which is similar to the order of magnitude reported by Norden and Weber (2009) for the correlations of their daily time series of CDS and bond spread changes.

Furthermore, we perform a unit root test on the time series of credit spreads. We apply three different tests to check whether the credit spread series are non-stationary. In particular, we use the Augmented Dickey-Fuller (ADF) test, the Kwiatkowski-Phillips-Schmidt-Shin (KPSS) test and the PhillipsPerron test. We find, in line with previous literature, that the hypothesis of non-stationarity for the levels of credit spreads is rejected only in very few cases at the $5 \%$ level of significance. Hence, our subsequent analysis is based on first-differenced series of spreads, which are no longer non-stationary.

\section{Methodology}

To determine which market is the "first to move", i.e. which market anticipates the credit spread changes observed in or implied from the other markets, we first employ a VAR model. This allows us to analyse the short-run dynamics of the price discovery process. Next, as credit spreads from the four markets should be linked in the long term as they represent prices of credit risk for the same firm, we also employ a VECM specification. Following an approach similar to Norden and Weber (2009), we perform an aggregate analysis to find out whether some markets, on average, lead the price discovery process of credit spreads. Then, in order to separate time series effects from the cross sectional effects, and hence allow the regression coefficients to change across firms, we also run the models on a firmby-firm basis.

The first step of our analysis is to apply a VAR model to describe changes in credit spreads for the four markets as given below:

\footnotetext{
${ }^{10}$ This means that large negative shocks are absent in the pre-crisis sub-sample and keep implied spreads from increasing.
} 


$$
\begin{aligned}
& \Delta C D S_{t}=\alpha_{1}+\sum_{j=1}^{p} \beta_{1 j} \Delta C D S_{t-j}+\sum_{j=1}^{p} \delta_{1 j} \Delta B C S_{t-j}+\sum_{j=1}^{p} \gamma_{1 j} \Delta E I S_{t-j}+\sum_{j=1}^{p} \varphi_{1 j} \Delta O I S_{t-j}+\varepsilon_{1 t} \\
& \Delta B C S_{t}=\alpha_{2}+\sum_{j=1}^{p} \beta_{2 j} \Delta C D S_{t-j}+\sum_{j=1}^{p} \delta_{2 j} \Delta B C S_{t-j}+\sum_{j=1}^{p} \gamma_{2 j} \Delta E I S_{t-j}+\sum_{j=1}^{p} \varphi_{2 j} \Delta O I S_{t-j}+\varepsilon_{2 t} \\
& \Delta E I S_{t}=\alpha_{3}+\sum_{j=1}^{p} \beta_{3 j} \Delta C D S_{t-j}+\sum_{j=1}^{p} \delta_{3 j} \Delta B C S_{t-j}+\sum_{j=1}^{p} \gamma_{3 j} \Delta E I S_{t-j}+\sum_{j=1}^{p} \varphi_{3 j} \Delta O I S_{t-j}+\varepsilon_{3 t} \\
& \Delta O I S_{t}=\alpha_{4}+\sum_{j=1}^{p} \beta_{4 j} \Delta C D S_{t-j}+\sum_{j=1}^{p} \delta_{4 j} \Delta B C S_{t-j}+\sum_{j=1}^{p} \gamma_{4 j} \Delta E I S_{t-j}+\sum_{j=1}^{p} \varphi_{4 j} \Delta O I S_{t-j}+\varepsilon_{4 t},
\end{aligned}
$$

where $\varepsilon_{1 t}, \varepsilon_{2 t}, \varepsilon_{3 t}, \varepsilon_{4 t}$ are i.i.d. error terms and CDS, BCS, EIS and OIS indicate CDS mid-quotes, bond credit spreads, equity implied spreads and option implied spreads, respectively.

Subsequently, to analyse whether the CDS, bond, equity and option markets are linked via a long run equilibrium relation, we also employ a VECM model. The model is specified as follows:

$$
\begin{aligned}
& \Delta C D S_{t}=\alpha_{1}+\lambda_{11} C E_{1}+\lambda_{12} C E_{2}+\lambda_{13} C E_{3}+\sum_{j=1}^{p} \beta_{1 j} \Delta C D S_{t-j} \\
& +\sum_{j=1}^{p} \delta_{1 j} \Delta B C S_{t-j}+\sum_{j=1}^{p} \gamma_{1 j} \Delta E I S_{t-j}+\sum_{j=1}^{p} \varphi_{1 j} \Delta O I S_{t-j}+\varepsilon_{1 t} \\
& \Delta B C S_{t}=\alpha_{2}+\lambda_{21} C E_{1}+\lambda_{22} C E_{2}+\lambda_{23} C E_{3}+\sum_{j=1}^{p} \beta_{2 j} \Delta C D S_{t-j} \\
& +\sum_{j=1}^{p} \delta_{2 j} \Delta B C S_{t-j}+\sum_{j=1}^{p} \gamma_{2 j} \Delta E I S_{t-j}+\sum_{j=1}^{p} \varphi_{2 j} \Delta O I S_{t-j}+\varepsilon_{2 t} \\
& \Delta E I S_{t}=\alpha_{3}+\lambda_{31} C E_{1}+\lambda_{32} C E_{2}+\lambda_{33} C E_{3}+\sum_{j=1}^{p} \beta_{3 j} \Delta C D S_{t-j} \\
& +\sum_{j=1}^{p} \delta_{3 j} \Delta B C S_{t-j}+\sum_{j=1}^{p} \gamma_{3 j} \Delta E I S_{t-j}+\sum_{j=1}^{p} \varphi_{3 j} \Delta O I S_{t-j}+\varepsilon_{3 t} \\
& \Delta O I S_{t}=\alpha_{4}+\lambda_{41} C E_{1}+\lambda_{42} C E_{2}+\lambda_{43} C E_{3}+\sum_{j=1}^{p} \beta_{4 j} \Delta C D S_{t-j} \\
& +\sum_{j=1}^{p} \delta_{4 j} \Delta B C S_{t-j}+\sum_{j=1}^{p} \gamma_{4 j} \Delta E I S_{t-j}+\sum_{j=1}^{p} \varphi_{4 j} \Delta O I S_{t-j}+\varepsilon_{4 t},
\end{aligned}
$$

where $\varepsilon_{1 t}, \varepsilon_{2 t}, \varepsilon_{3 t}, \varepsilon_{4 t}$ are i.i.d. error terms. The $C E_{i}$ terms are cointegration equations defined as: 


$$
\begin{aligned}
& C E_{1}=C D S_{t-1}-\phi_{11}-\phi_{21} O I S_{t-1} \\
& C E_{2}=B C S_{t-1}-\phi_{12}-\phi_{22} O I S_{t-1} \\
& C E_{3}=E I S_{t-1}-\phi_{13}-\phi_{23} O I S_{t-1}
\end{aligned}
$$

We define the three cointegration equations as in (9) to (11) where long run relationship are measured in relation to the option market because we are particularly interested in analysing the role of the option market (against the other markets) in the price discovery of credit risk, which has been the focus on recent research (e.g. Alexander and Kaeck, 2008, Berndt and Ostrovnaya, 2008, and Cao et al. 2010). In order to quantify the share of the price discovery attributable to each market, we follow Norden and Weber (2009) and rely on the measure of price discovery introduced by Gonzalo and Granger (1995).

The general representation in equations (5) to (11) only applies to the companies for which the maximum number of cointegrating equations (three) is found. To determine the contribution to price discovery of the various markets, one can focus on the statistical significance and sign of the error correction coefficients $\lambda$ 's. For instance, if the option market leads the discovery of the price of credit risk, the $\lambda_{i j}$ 's in equations (5) to (7), will be negative and statistically significant as all the other three markets will adjust when they deviate from the option market. On the other hand, if the option market is the least important in the price discovery process then all the $\lambda$ 's in equation (8) will be positive and statistically significant as the option market adjusts when it deviates from the other markets. If all $\lambda_{i j}$ 's in equations (5) to (7) and all the $\lambda$ 's in equation (8) are significant and with the signs indicated above, then price discovery takes place, to some degree, in all markets. This above is summarised in Table 3.

\section{Results}

\subsection{Price discovery: the short-run dynamics}

We use a VAR model, as defined in equations (1) to (4), to investigate the short-run dynamics of credit spreads price discovery in terms of lead-lags relationships. Each variable in the system is treated as endogenous and lead-lags effects can be captured by examining the significance of the coefficients of each explanatory variable. Firstly, we estimate the VAR model in a fixed effect panel framework in order to verify whether on aggregate it is possible to identify any leading market. The selection of the number of lags for each variable is based on the Schwartz criterion. Results are shown in Table 4. From the panel regression it is difficult to detect general patterns, with few exceptions. We can see that lagged CDS spread changes systematically lead spread changes in the bond market in all 
periods and that bond and equity spread changes are the only ones to be consistently autocorrelated in all periods.

A more insightful analysis can be performed when we separate the cross sectional from the time series effects in the panel. We do so by estimating a VAR model for each firm in our sample and by running Granger causality tests to determine the leading behaviour of the markets under consideration. Results are presented in Table 5, where we show the number of cases for which the lagged coefficients of individual markets are jointly different from zero. The last column shows the total number of instances in which a market Granger causes the one of the other markets. We can see that in 46 instances the option market leads another market during the sub-prime crisis, followed by the equity and bond market (with 33 and 32 firms, respectively). The dominance of the option market appears to be driven by its strong influence on the equity market. Options exhibit a strong short term leading behaviour also in the pre-crisis period and the sovereign debt crisis where, however, it ranks second after the CDS market in both instances. The overall picture from Table 5 is that the degree of interdependence among markets, as measured by lead-lag relationships at the firm level, increases substantially in times of high uncertainty. The number of occasions in which a market Granger causes another grows from 60 in the pre-crisis period to more than double that amount (137) in the sub-prime crisis and by $80 \%$ (108) in the sovereign debt crisis.

\subsection{Price discovery: the long-run dynamics}

In this section we analyse how credit spreads react to deviations from the long-run equilibrium relationship among credit spreads obtained from the four markets. One way to do so when credit spreads are non-stationary is to introduce an error correction term in the VAR model and estimate a standard VECM. The results of the Johansen cointegration test for each of the 30 companies in our sample shows that the maximum number of cointegrating relationships (that is three) is found for 20 firms (out of 30). ${ }^{11}$ We then focus our attention on these 20 companies to study the long run price discovery for the four markets. ${ }^{12}$ Specifically, we analyse the coefficients on the error correction terms introduced in equations (5) to (8).

Similarly to the previous VAR analysis, we first report aggregate results for a VECM estimated as a panel, which includes all companies in our restricted sample of 20 firms. Coefficient estimates and corresponding p-values are shown in Table 6. The interpretation of the error correction coefficients to make inference on long run price discovery is summarised in Table 3. From Table 6 we observe that in the pre-crisis period (Panel A) option spreads adjust to both CDS spreads and equity implied spreads as $\lambda_{41}$ and $\lambda_{43}$ are both highly significant. We also find that options lead bonds as $\lambda_{42}$ is insignificant, whereas $\lambda_{22}$ is highly significant. During the sub-prime crisis (Panel B), the option

\footnotetext{
${ }^{11}$ Results of the Johansen test are available on request.

${ }^{12}$ Note that of these 20 firms, 10 are based in Europe, whilst the remaining 10 are US-based.
} 
market leads the equity market while option and bonds contribute to the long run price discovery of each other. We do not find evidence of option implied credit spreads and CDS spreads reacting to temporary divergences between the two markets. In the sovereign crisis (Panel C), options lead both CDS and bond markets as $\lambda_{11}$ and $\lambda_{22}$ are significant. The main conclusion to draw from the VECM analysis seems to be that is that the option market has an important role in influencing price formation in other markets in periods of stress.

However, the above analysis gives only a partial picture of market interactions because (i) as mentioned before, time series and cross-sectional effects are co-mingled and (ii) long run price discovery is analysed from the point of view of the option market. To address (i) we run a VECM at the firm level. Results are shown in Table 7 Panel A. Median lambdas across firms again support our previous conclusions with the option market having a dominant role: in the sub-prime crisis relative to all other markets, and in the sovereign crisis with respect to CDS and bonds. We then tackle (ii) by estimating a Gonzalo-Granger (GG) measure of long run price discovery by taking into account the leading behaviour of each market in relation to every other market (not only the option market). GG measures are reported in Table 7 Panel B. Here the conclusions are rather different and surprising. Price discovery in the sub-prime crisis is led by bonds and CDSs whereas in the sovereign crisis and the pre-crisis period the leaders are CDSs and equities. A combined interpretation of Panel A and B leads us to conclude that although options may lead credit risk assessments in other markets in periods of high uncertainty, the information contained in them is not the only signal that affects credit spread changes in other markets when we look at long run dynamics. Results on the GG measure reveal that deviations from the long run relationship with option implied spreads, although accounted for and often significant, are not the most important contributing factor to credit risk price formation. This is in sharp contrast to our VAR results on short run price discovery and add a different dimension to our VECM results.

\subsection{Comments}

One of the findings of our analysis refers to the increasing role of the bond market in the price discovery, both short term and long term, during the sub-prime crisis. This may be related to the liquidity problems faced by market participants during the recent financial crisis, as they were forced to deleverage their corporate bond positions to re-pay their short term exposures, as discussed in Bai and Collin-Dufresne (2011).

The dramatic fall in the price discovery of the equity market during the crisis revealed by the GG measure may be due to a substantial increase in hedging costs. Das and Hanouna (2009) show that equity hedging costs increase when markets are volatile. When stock prices fall, hedge ratios rise, thus determining an increase in hedging costs, worsened by the presence of frictions such as illiquidity in the equity market. This could be a reason why, under such circumstances, professional investors may 
channel their trades via different trading venues such as bond, CDS and option markets. A second possible reason for the lesser role of the equity market relative to the other markets during the crisis may be related to the presence of informed trading and insider trading documented for the derivatives markets by Pan and Poteshman (2006) and Acharya and Johnson (2007). In particular, the former study focuses on the option market and documents how information on option trading volumes could help predict the future movements of equity prices, which supports a greater importance of options in the price formation process. The latter study highlights how insider trading could be the reason for the superiority of the CDS market over the equity market in terms of information revelation in the presence of negative credit news. However, although the above offers a plausible explanation for our long run price discovery results, it is unclear why they are contradicted by our price discovery findings in the short run where equities appear to be an important market alongside bonds during the sub-prime crisis.

If we focus on the long run relationships alone, the dominant role of both the CDS and equity markets during stable periods is in line with the results of Longstaff et al. (2003). Forte and Peña (2009) and Norden and Weber (2009) find a clear leading role for the equity market. However, these studies have not considered the option market in their analyses. Our findings support those of Berndt and Ostrovnaya (2008) and Cao et al. (2010), who document the importance of the information flow from the option market to the CDS and equity markets. Finally, our results are in line with those of Zhu (2006) and Blanco et al. (2005), who observe that in the pre-crisis period the bond market is dominated by the CDS market in terms of price discovery.

\section{Robustness tests}

We analyse the US and European samples separately in order to investigate whether the price discovery process is robust across regions. Results from the firm-by-firm VECM are reported in Table 8. By focusing on the pairwise analysis between option spreads and spreads derived from other markets, Panel A and C (on error correction coefficients) shows that, for both the US and European firms, results are very similar to those reported in Table 7 for the whole sample.

Some differences arise when we investigate the joint price discovery of the four markets with the GG measure (Panels B and D of Table 8). In particular, the main differences (as compared with the results in Table 7) relate to the sub-prime crisis. While the bond market is the most important one in the European sample, it is the CDS market that has a leading role in the US. However, in general, the price discovery of bonds increases during this sub-period, in line with what has been documented by Bai and Collin-Dufresne (2011). We also note that during the pre-crisis period the option market seems to have a greater share of price discovery in Europe than in the US market. This is consistent 
with the leading role of options over equities in the short term found with the VAR analysis. Indeed, in Panel A of Table 5, 10 of the 12 significant lagged changes of option spreads that are statistically significant in explaining changes in equity spreads, are due to European companies included in our analysis.

We do an additional robustness test by splitting the third sub-sample (between August 2009 and December 2012), which includes the sovereign debt crisis, into 2 sub-periods. Our purpose is to isolate the periods of low volatility for corporate spreads from the periods of high volatility corresponding to the heat of the sovereign debt crisis. For example, by observing Figure 1 more closely, we notice that from August 2010 until July 2011, the option market as represented by our sample of companies experienced a period of low volatility. From August 2011 till the end of our sample, there is a marked increase in volatility. We then re-run our analysis separately for these two sub-periods to see whether we can identify any differences in the price discovery behaviour of corporate credit spreads. We find that the results for the two sub-periods are qualitatively similar to those in Table 7. Hence, we conclude that our results obtained during the longer sovereign crisis sample are valid for the entire duration of this sub-period.

Finally, we also re-compute equity implied spreads by using a 250-day historical volatility (in addition to the 40-day rolling window) as in Bharath and Shumway (2008) and Vassalou and Xing (2004) and we run again a VAR panel regression which includes all firms in our sample. The results do not differ qualitatively from those obtained in Table 4.

\section{Conclusions}

This paper analyses the price discovery in credit spreads obtained or implied from the option, CDS, bond and equity markets. In our analysis we distinguish between short term and long term price discovery in the four markets. Short term price discovery measures indicate that the option market clearly influences credit risk pricing in the other markets in periods of highest uncertainty. In calmer conditions, even though options are still important, CDSs become the dominant market. When we look at the influence on credit spread changes of deviations from long run equilibrium relationships across markets, options are still important but no longer have a prominent role regardless of market conditions. Specifically, CDSs and equities lead the long run price discovery of credit spreads during the pre-crisis period and the sovereign crisis. However, the bond market becomes more influential in the sub-prime crisis and especially in our European sample, where it appears as the leading market. In our US sample, the CDS market leads the long run price discovery during the sub-prime crisis. 
Relative to previous research, by focusing simultaneously on all markets that have been identified as containing information on credit spreads, our analysis gives a fuller characterisation of the process that leads to the formation of the price for credit risk. Interestingly, our Granger causality tests show the presence of strong interlinkages across markets especially during the sub-prime crisis. Overall, it is difficult to draw overarching conclusions except that the price discovery of credit spreads changes quite substantially over time, across regions and across reference entities. This implies, for example, that hedging or trading strategies based on pre-determined interactions among the above markets may only have short lived validity. An interesting line of future research could focus on the occasional discrepancies that can be observed between short term and long term price discovery behaviour. A greater understanding of this puzzling evidence, especially in crisis periods, could help us devise more effective leading indicators of market turbulence.

\section{Appendix}

\section{CreditGrades Model}

According to the model, the recovery rate $L$ follows a lognormal distribution with mean $\bar{L}$ and standard deviation $\lambda$ where

$\bar{L}=E[L]$ and

$\lambda^{2}=\operatorname{Var}[\log (L)]$, such that

$L D=\bar{L} D e^{\lambda Z-\lambda^{2} / 2}$

where $\bar{L}$ is the mean global recovery rate, $\lambda$ is the percentage standard deviation of the default barrier, $D$ is the company's debt-per-share and $Z$ is a standard normal random variable which is known at the time of default only.

The debt-per-share $D$ is based on financial data from consolidated statements and is defined as the ratio of liabilities to the number of outstanding shares issued by a specific firm, where liabilities are defined as follows:

Liabilities $=$ Financial__Debt - Minority__nterest and

Financial__Debt $=S T D e b t+L T D e b t+0.5 *\left(O t h e r \_S T D e b t+O t h e r \_L T D e b t\right)$

where Minority _ Interest represents the portion of the stock of subsidiary corporations not owned by the parent company; STDebt and LTDebt are short-term and long-term interest-bearing 
obligations; Other_STDebt and Other_LTDebt are short-term and long-term obligations that do not bear explicit interest.

The number of outstanding shares is defined as the sum of common shares and preferred shares:

Number_shares $=$ common_shares + preferred_shares, where

common_shares $=\frac{\text { market_cap }}{S}$, and

preferred_shares $=\frac{\text { preferred_equity }}{S}$

market_cap and preferred_equity represent the current market capitalization and the book value of the preferred shares, respectively. $S$ is the price of the common stock. The final formula for the debt-per-share $D$ is then given by:

$D=\frac{\text { Liabilities }}{\text { Number_shares }}$

The company's asset value is assumed to follow a geometric Brownian motion:

$\frac{d V_{t}}{V_{t}}=\mu d t+\sigma d W_{t}$

where $\mu$ is the asset drift, $\sigma$ is the asset volatility and $W$ is a standard Brownian motion.

The survival probability of the company at any time $t$ is given by the probability that the asset value (A10) does not hit the barrier defined in (A3) before time $t$ :

$P(t)=\phi\left(-\frac{A_{t}}{2}+\frac{\log (d)}{A_{t}}\right)-d \cdot \phi\left(-\frac{A_{t}}{2}-\frac{\log (d)}{A_{t}}\right)$

where

$d=\frac{V_{0} e^{\lambda^{2}}}{\bar{L} D}$ and

$A_{t}^{2}=\sigma^{2} t+\lambda^{2}$

The asset value and asset volatility can be proxied by market observables parameters. In fact, it can be assumed that at time $t=0$ : 
$V=S+\bar{L} D$ and

$\sigma=\sigma_{S} \frac{S}{S+\bar{L} D}$

such that (A12) and (A13) can be written as:

$d=\frac{S+\bar{L} D}{\bar{L} D} e^{\lambda^{2}}$ and

$A_{t}^{2}=\left(\sigma_{S} \frac{S}{S+\bar{L} D}\right)^{2} t+\lambda^{2}$

where $\sigma_{S}$ is the stock volatility. Finally, the survival probability is converted to a credit spread as follows:

$E I S=r(1-R) \frac{1-P(0)+e^{r \xi}(G(t+\xi)-G(\xi))}{P(0)-P(t) e^{-r t}-e^{r \xi}(G(t+\xi)-G(\xi))}$

where $\xi=\frac{\lambda^{2}}{\sigma^{2}}$

and, following Rubinstein and Reiner (1991),

$G(u)=d^{z+1 / 2} \phi\left(-\frac{\log (d)}{\sigma \sqrt{u}}-z \sigma \sqrt{u}\right)+d^{-z+1 / 2} \phi\left(-\frac{\log (d)}{\sigma \sqrt{u}}+z \sigma \sqrt{u}\right)$

with $z=\sqrt{1 / 4+2 r / \sigma^{2}}$.

In particular, an estimate of the asset volatility can be obtained by using the following relationship: ${ }^{13}$

$\sigma_{S}=\sigma\left(1+\frac{\bar{L} D e^{r t}}{S}\right)$

where $\sigma_{S}$ is a daily time series of at-the-money equity option implied volatilities. By inverting the formula and solving for the unknown asset volatility $\sigma$, we can calculate an option-implied spread (OIS) by using again equation (A18).

\section{References}

${ }^{13}$ See Stamicar and Finger (2006) for a comprehensive discussion on different ways to extend the original CreditGrades model. 
Acharya, V.V., Johnson, T.C., 2007. Insider trading in credit derivatives. Journal of Financial Economics 84, 110-141.

Alexander, C., Kaeck, A., 2008. Regime dependent determinants of credit default swap spreads. Journal of Banking and Finance 32, 1008-1021.

Bai, J., Collin-Dufresne, P., 2011. The CDS-bond basis during the financial crisis of 2007-2009. Working Paper. Available at SSRN: http://ssrn.com/abstract=1785756

Bharath,S.T., Shumway, T., 2008. Forecasting default with the Merton distance to default model. Review of Financial Studies 21, 1339-1369.

Basel Committee on Banking Supervision, 2009. Guidelines for computing capital for incremental risk in the trading book. Bank for International Settlements, July.

Berndt, A., Ostrovnaya, A., 2008. Do equity markets favour credit market news over options market news? Working Paper, Carnegie Mellon University.

Blanco, F., Brennan, S., Marsh, I.W., 2005. An empirical analysis of the dynamic relationship between investment grade bonds and credit default swaps. Journal of Finance 60, 2255-2281.

Cao, C., Yu, F., Zhong, Z., 2010. The information content of option-implied volatility for credit default swap valuation. Journal of Financial Markets 13, 321-343.

Cao, C., Yu, F., Zhong, Z., 2011. Pricing credit default swaps with option-implied volatility. Financial Analysts Journal 67, 67-76.

Chakravarty, S., Gulen, H., Mayhew, S., 2004. Informed trading in stock and option markets. Journal of Finance $59,1235-1257$.

Chava, S., Purnanandam, A., 2010. Is default risk negatively related to stock returns? Review of Financial Studies 23, 2523-2559.

Collin-Dufresne, P., Goldstein, R.S., Martin, J.S.,2001. The determinants of credit spread changes. Journal of Finance 56, 2177-2207.

CreditGrades Technical Document, 2002. http://www.creditgrades.com/resources/pdf/CGtechdoc.pdf

Cremers, M., Driessen, J., Maenhout, P., Weinbaum, D., 2008. Individual stock option prices and credit spreads. Journal of Banking and Finance 32, 2706-2715.

Das, S.R., Hanouna, P., 2009. Hedging credit: equity liquidity matters. Journal of Financial Intermediation 18, 112-123.

Das, S.R., Kalimipalli, M., Nayak, S., 2012. Did CDS trading improve the market for corporate bonds? Working Paper. Available at SSRN: http://ssrn.com/abstract=1782298

Dichev, I.D., 1998. Is the risk of bankruptcy a systematic risk? Journal of Finance 53, 1131-1147.

Duarte, J., Longstaff, F., Yu, F., 2007. Risk and return in fixed income arbitrage: nickels in front of a steamroller? Review of Financial Studies 20, 769-811.

Elkamhi, R., Jacobs, K., Langlois, H., Ornthanalai, C., 2012. Accounting information releases and CDS spreads. Working Paper. Available at SSRN: http://ssrn.com/abstract=1874127

Eom, Y., Helwege, J., Huang, J., 2004. Structural models of corporate bond pricing: an empirical analysis. Review of Financial Studies 17, 499-544.

Ericsson, J., Reneby, J., Wang, H., 2005. Can structural models price default risk? New evidence from bond and credit derivative markets. Working Paper, McGill University. 
Fisher, L., 1959. Determinants Of Risk Premiums On Corporate Bonds. Journal of Political Economy 67(3), 217-237.

Forte, S., Peña, J.I., 2009. Credit spreads: An empirical analysis on the informational content of stocks, bonds, and CDS. Journal of Banking and Finance 33, 2013-2025

Gonzalo, J., Granger, C.W.J., 1995. Estimation of common long-memory components in cointegrated systems. Journal of Business and Economics Statistics 13, 27-36.

Hamalainen, P., Pop, A., Hall, M., Howcroft, B., 2012. Did the market signal impending problems at Northern Rock? An analysis of four financial instruments. European Financial Management 18, 68-87.

Hilscher, J., Pollet, J.M., Wilson, M., 2013. Are credit default swaps a sideshow? Evidence that information flows from equity to CDS markets. Journal of Financial and Quantitative Analysis, forthcoming.

Houweling, P., Vorst, T., 2005. Pricing default swaps: empirical evidence. Journal of International Money and Finance 24, 1200-1225.

Huang, J.Z., Huang, M., 2012. How much of corporate-treasury yield spread is due to credit risk? Review of Asset Pricing Studies 2, 153-202.

Hull, J., Nelken, I., White, A., 2005. Merton's model, credit risk and volatility skews. Journal of Credit Risk 1, 3-28.

Johnson, R.E., 1967. Term Structures Of Corporate Bond Yields As A Function Of Risk Of Default. Journal of Finance 22(2), 313-345.

Jones, E.P., Mason, S.P., Rosenfeld, E., 1984. Contingent claims analysis of corporate capital structures: an empirical investigation. Journal of Finance 39, 611-625.

JPMorgan, 2006. Credit derivatives handbook. Corporate Quantitative Research.

Kapadia, N., Pu, X., 2012. Limited arbitrage between equity and credit markets. Journal of Financial Economics 105, 542-564.

Kealhofer, S., 2003a. Quantifying credit risk I: Default prediction. Financial Analysts Journal 59, 30-44.

Kealhofer, S., 2003b. Quantifying credit risk II: Debt valuation. Financial Analysts Journal 59, 78-92.

Longstaff, F.A., Mithal, S., Neis, E., 2003. The credit-default swap market: is credit protection priced correctly? Working Paper, University of California, Los Angeles.

Mayordomo, S., Peña, J.I., Schwartz, E.S., 2013. Are all credit default swap databases equal? European Financial Management, forthcoming.

Merton, R.C., 1974. On the pricing of corporate debt: the risk structure of interest rates. Journal of Finance 29, 449-470.

Moody’s, 2011. Corporate default and recovery rates, 1920-2010. Moody’s Investor Service, February.

Norden, L., Weber, M., 2009. The co-movement of credit default swap, bond and stock markets: an empirical analysis. European Financial Management 15, 529-562.

Pan, J., Poteshman, A.M., 2006. The information in option volume for future stock prices. Review of Financial Studies 19, 871-908.

Sarig, O. and Warga, A., 1989. Some Empirical Estimates Of The Risk Structure Of Interest Rates. Journal of Finance 44(5), 1351-1360. 
Rubinstein, M. and Reiner E., 1991. Breaking down the barriers. RISK 4 (September), 28-35.

Stamicar, R., Finger, C., 2006. Incorporating equity derivatives into the CreditGrades model. Journal of Credit Risk 2, 1-20.

Vassalou, M., Xing, M.Y., 2004. Default risk in equity returns. Journal of Finance 59, 831-868.

Yu, F., 2006. How profitable is capital structure arbitrage? Financial Analysts Journal 62, 47-62.

Zhu, H., 2006. An empirical comparison of credit spreads between the bond market and the credit default swap market. Journal of Financial Services Research 29, 211-235. 


\section{Table 1. Summary statistics for credit spread levels}

This table reports summary statistics for the time series of daily credit spreads obtained from the CDS, bond, equity and option markets. In particular, we report the $10 \%$, $50 \%$ and $90 \%$ quantiles and the standard deviation (SD). We also differentiate by sub-period and region. Data on spreads are in basis points and are based on a sample of 30 firms. $10 \%, 50 \%$ and $90 \%$ indicate quantiles of the distribution of credit spreads.

\begin{tabular}{|c|c|c|c|c|c|c|c|c|c|c|c|c|c|c|c|c|c|c|}
\hline & & \multirow[b]{2}{*}{ Obs. } & \multicolumn{4}{|c|}{ CDSs } & \multicolumn{4}{|c|}{ Bonds } & \multicolumn{4}{|c|}{ Equities } & \multicolumn{4}{|c|}{ Options } \\
\hline & & & $10 \%$ & $50 \%$ & $90 \%$ & StDev & $10 \%$ & $50 \%$ & $90 \%$ & StDev & $10 \%$ & $50 \%$ & $90 \%$ & StDev & $10 \%$ & $50 \%$ & $90 \%$ & StDev \\
\hline \multirow[t]{4}{*}{ Sample } & Pre-crisis period & 11373 & 9.00 & 23.40 & 72.50 & 127.07 & 2.85 & 22.97 & 75.26 & 65.41 & 0.00 & 0.45 & 86.79 & 306.73 & 0.00 & 1.68 & 64.07 & 314.50 \\
\hline & Sub-prime crisis & 13820 & 32.00 & 86.00 & 343.80 & 657.85 & 21.85 & 102.65 & 389.05 & 300.56 & 0.32 & 63.55 & 1032.1 & 938.32 & 0.58 & 64.79 & 859.41 & 606.86 \\
\hline & Sovereign crisis & 22443 & 46.74 & 89.19 & 361.54 & 153.25 & 21.56 & 73.89 & 342.44 & 145.26 & 0.05 & 20.45 & 356.94 & 189.74 & 0.18 & 26.66 & 353.48 & 382.54 \\
\hline & All & 47636 & 19.50 & 70.50 & 310.00 & 379.10 & 11.41 & 61.62 & 315.42 & 200.35 & 0.01 & 14.51 & 453.20 & 555.38 & 0.04 & 20.52 & 416.20 & 454.70 \\
\hline \multicolumn{19}{|c|}{28} \\
\hline \multirow[t]{2}{*}{ Region } & US & 14928 & 14.00 & 56.01 & 604.29 & 652.31 & 6.37 & 61.75 & 501.81 & 317.20 & 0.00 & 9.15 & 788.79 & 546.50 & 0.00 & 15.94 & 703.39 & 670.28 \\
\hline & Europe & 32708 & 23.00 & 76.16 & 203.11 & 95.65 & 15.22 & 61.59 & 221.83 & 95.28 & 0.04 & 17.12 & 386.54 & 556.15 & 0.17 & 22.03 & 340.28 & 299.89 \\
\hline
\end{tabular}

\section{Table 2. Contemporaneous correlation of credit spreads changes}

This table reports average Pearson correlation coefficients ( $\rho$ ) estimated for changes of credit spreads obtained from the credit default swap market (CDS), the bond market (BCS), the equity market (EIS) and the option market (OIS). We differentiate by sub-period and region.

\begin{tabular}{|c|c|c|c|c|c|c|c|}
\hline & & $\rho(\triangle \mathrm{CDS}, \triangle \mathrm{BCS})$ & $\rho(\Delta \mathrm{CDS}, \Delta \mathrm{EIS})$ & $\rho(\Delta \mathrm{CDS}, \Delta \mathrm{OIS})$ & $\rho(\Delta \mathrm{BCS}, \Delta \mathrm{EIS})$ & $\rho(\Delta \mathrm{BCS}, \Delta \mathrm{OIS})$ & $\rho(\Delta \mathrm{EIS}, \Delta \mathrm{OIS})$ \\
\hline \multirow[t]{4}{*}{ Sample } & Pre-crisis period & 0.11 & 0.16 & 0.18 & 0.05 & 0.04 & 0.53 \\
\hline & Sub-prime crisis & 0.19 & 0.04 & 0.05 & 0.07 & 0.07 & 0.19 \\
\hline & Sovereign crisis & 0.14 & 0.12 & 0.05 & 0.03 & 0.01 & 0.01 \\
\hline & All & 0.17 & 0.04 & 0.03 & 0.06 & 0.04 & 0.10 \\
\hline \multirow[t]{2}{*}{ Region } & US & 0.17 & 0.11 & 0.03 & 0.17 & 0.04 & 0.06 \\
\hline & Europe & 0.14 & -0.01 & 0.07 & 0.00 & 0.03 & 0.16 \\
\hline
\end{tabular}


Table 3. Long run price discovery: interpretation of error correction coefficients.

The table shows how lambda coefficients in the VECM model, equations (5) to (8) should be interpreted to do inference about long run price discovery.

\begin{tabular}{c|cc}
\hline \multicolumn{2}{l}{ Option market leads } \\
\hline CDS & $\lambda_{1,1}<0$ & $\lambda_{4,1}$ not significant \\
Bond & $\lambda_{2,2}<0$ & $\lambda_{4,2}$ not significant \\
Equity & $\lambda_{3,3}<0$ & $\lambda_{4,3}$ not significant \\
\hline \multicolumn{3}{c}{} \\
\hline Option market follows \\
\hline CDS & $\lambda_{1,1}$ not significant & $\lambda_{4,1}>0$ \\
Bond & $\lambda_{2,2}$ not significant & $\lambda_{4,2}>0$ \\
Equity & $\lambda_{3,3}$ not significant & $\lambda_{4,3}>0$ \\
\hline
\end{tabular}




\section{Table 4. Aggregate price discovery analysis: VAR results}

This table reports results obtained from the estimation of a VAR fixed-effect panel regression on daily changes in credit spreads from the credit default swap market (CDS), the bond market (BCS), the equity market (EIS) and the option market (OIS), based on equations (1) - (4). Regressions are estimated on a sample of 30 firms over three different periods, which include a pre-crisis period (January 2006 - July 2007), the sub-prime crisis (August 2007 - July 2009) and the sovereign crisis (August 2009 - December 2012). P-values less than 5\% are indicated in bold.

\begin{tabular}{|c|c|c|c|c|c|c|c|c|}
\hline \multirow{2}{*}{ Dep.Var. } & \multicolumn{2}{|c|}{$\Delta \mathrm{CDS}_{\mathrm{t}}$} & \multicolumn{2}{|c|}{$\Delta \mathrm{BCS}_{\mathrm{t}}$} & \multicolumn{2}{|c|}{$\Delta \mathrm{EIS}_{\mathrm{t}}$} & \multicolumn{2}{|c|}{$\Delta \mathrm{OIS}_{\mathrm{t}}$} \\
\hline & Coeff. & p-val. & Coeff. & $p$-val. & Coeff. & $p$-val. & Coeff. & $p$-val. \\
\hline \multicolumn{9}{|c|}{ Panel A: Pre-crisis period } \\
\hline$\Delta \mathrm{CDS}_{\mathrm{t}-1}$ & -0.17 & 0.069 & 0.05 & 0.184 & -0.11 & 0.181 & -0.05 & 0.608 \\
\hline$\Delta \mathrm{CDS}_{\mathrm{t}-2}$ & -0.11 & 0.115 & 0.06 & 0.107 & -0.15 & 0.080 & 0.03 & 0.800 \\
\hline$\Delta \mathrm{CDS}_{\mathrm{t}-3}$ & -0.08 & 0.270 & 0.10 & 0.000 & -0.00 & 0.995 & 0.05 & 0.708 \\
\hline$\Delta \mathrm{CDS}_{\mathrm{t}-4}$ & -0.09 & 0.237 & 0.09 & 0.008 & 0.18 & 0.041 & 0.30 & 0.004 \\
\hline$\Delta \mathrm{BCS}_{\mathrm{t}-1}$ & 0.09 & 0.005 & -0.53 & 0.000 & 0.05 & 0.234 & 0.11 & 0.024 \\
\hline$\Delta \mathrm{BCS}_{\mathrm{t}-2}$ & 0.07 & 0.050 & -0.31 & 0.000 & 0.06 & 0.196 & 0.10 & 0.086 \\
\hline$\Delta \mathrm{BCS}_{\mathrm{t}-3}$ & 0.09 & 0.054 & -0.14 & 0.000 & 0.01 & 0.792 & 0.04 & 0.620 \\
\hline$\Delta \mathrm{BCS}_{\mathrm{t}-4}$ & 0.07 & 0.029 & -0.09 & 0.005 & -0.06 & 0.258 & -0.07 & 0.259 \\
\hline$\Delta \mathrm{EIS}_{\mathrm{t}-1}$ & 0.07 & 0.002 & 0.04 & 0.003 & 0.06 & 0.234 & 0.20 & 0.001 \\
\hline$\Delta \mathrm{EIS}_{\mathrm{t}-2}$ & 0.01 & 0.706 & 0.02 & 0.144 & 0.00 & 0.926 & 0.02 & 0.707 \\
\hline$\Delta \mathrm{EIS}_{\mathrm{t}-3}$ & 0.00 & 0.799 & 0.01 & 0.519 & -0.07 & 0.019 & -0.05 & 0.236 \\
\hline$\Delta \mathrm{EIS}_{\mathrm{t}-4}$ & 0.07 & 0.015 & 0.02 & 0.121 & 0.03 & 0.329 & 0.06 & 0.178 \\
\hline$\Delta \mathrm{OIS}_{\mathrm{t}-1}$ & 0.04 & 0.040 & 0.01 & 0.113 & 0.01 & 0.742 & -0.23 & 0.000 \\
\hline$\Delta \mathrm{OIS}_{\mathrm{t}-2}$ & 0.00 & 0.936 & 0.01 & 0.127 & 0.04 & 0.123 & -0.09 & 0.041 \\
\hline$\Delta \mathrm{OIS}_{\mathrm{t}-3}$ & 0.02 & 0.267 & 0.00 & 0.752 & 0.01 & 0.727 & -0.05 & 0.268 \\
\hline$\Delta \mathrm{OIS}_{\mathrm{t}-4}$ & -0.01 & & -0.00 & 0.705 & -0.01 & 0.666 & -0.06 & 0.101 \\
\hline Const. & 0.03 & & -0.05 & 0.414 & -0.01 & 0.918 & -0.07 & 0.620 \\
\hline Obs. & 9501 & & 9501 & & 9501 & & 9501 & \\
\hline $\mathrm{R}^{2}$ & 0.085 & & 0.243 & & 0.030 & & 0.061 & \\
\hline \multicolumn{9}{|c|}{ Panel B: Sub-prime crisis } \\
\hline$\Delta \mathrm{CDS}_{\mathrm{t}-1}$ & 0.13 & 0.447 & 0.11 & 0.028 & -0.10 & 0.102 & 0.03 & 0.823 \\
\hline$\Delta \mathrm{CDS}_{\mathrm{t}-2}$ & 0.25 & 0.035 & 0.11 & 0.001 & 0.04 & 0.277 & 0.07 & 0.267 \\
\hline$\Delta \mathrm{CDS}_{\mathrm{t}-3}$ & 0.13 & 0.319 & 0.04 & 0.258 & -0.01 & 0.730 & 0.02 & 0.775 \\
\hline$\Delta \mathrm{CDS}_{\mathrm{t}-4}$ & 0.12 & 0.347 & 0.04 & 0.108 & 0.01 & 0.659 & 0.00 & 0.957 \\
\hline$\Delta \mathrm{BCS}_{\mathrm{t}-1}$ & 0.19 & 0.004 & -0.21 & 0.002 & -0.02 & 0.668 & 0.31 & 0.003 \\
\hline$\Delta \mathrm{BCS}_{\mathrm{t}-2}$ & 0.00 & 0.987 & -0.07 & 0.202 & 0.04 & 0.539 & 0.27 & 0.057 \\
\hline$\Delta \mathrm{BCS}_{\mathrm{t}-3}$ & -0.07 & 0.432 & -0.05 & 0.229 & 0.12 & 0.027 & 0.34 & $\mathbf{0 . 0 3 8}$ \\
\hline$\Delta \mathrm{BCS}_{\mathrm{t}-4}$ & -0.14 & 0.122 & 0.00 & 0.947 & 0.09 & 0.095 & 0.13 & 0.298 \\
\hline$\Delta \mathrm{EIS}_{\mathrm{t}-1}$ & 0.02 & 0.048 & -0.00 & 0.910 & 0.22 & 0.140 & -0.53 & 0.223 \\
\hline$\Delta \mathrm{EIS}_{\mathrm{t}-2}$ & 0.01 & 0.620 & -0.00 & 0.759 & 0.20 & 0.033 & -0.13 & 0.660 \\
\hline$\Delta \mathrm{EIS}_{\mathrm{t}-3}$ & -0.00 & 0.900 & -0.00 & 0.799 & -0.02 & 0.768 & 0.05 & 0.729 \\
\hline$\Delta \mathrm{EIS}_{\mathrm{t}-4}$ & -0.01 & 0.170 & 0.00 & 0.756 & 0.14 & 0.027 & -0.17 & 0.361 \\
\hline$\Delta \mathrm{OIS}_{\mathrm{t}-1}$ & -0.00 & 0.883 & 0.01 & 0.239 & 0.18 & 0.016 & -0.04 & 0.859 \\
\hline$\Delta \mathrm{OIS}_{\mathrm{t}-2}$ & -0.01 & 0.050 & 0.01 & 0.094 & 0.13 & 0.000 & -0.03 & 0.800 \\
\hline$\Delta \mathrm{OIS}_{\mathrm{t}-3}$ & -0.01 & 0.025 & 0.01 & 0.135 & 0.01 & 0.844 & -0.09 & 0.360 \\
\hline$\Delta \mathrm{OIS}_{\mathrm{t}-4}$ & -0.00 & 0.527 & 0.00 & 0.270 & -0.00 & 0.758 & 0.02 & 0.662 \\
\hline Const. & 0.23 & 0.568 & 0.41 & 0.121 & 0.16 & 0.864 & 1.78 & 0.404 \\
\hline Obs. & 11329 & & 11329 & & 11329 & & 11329 & \\
\hline $\mathrm{R}^{2}$ & 0.160 & & 0.076 & & 0.307 & & 0.110 & \\
\hline
\end{tabular}




\section{Table 4 - continued}

\begin{tabular}{|c|c|c|c|c|c|c|c|c|}
\hline \multicolumn{9}{|c|}{ Panel C: Sovereign crisis } \\
\hline$\Delta \mathrm{CDS}_{\mathrm{t}-1}$ & 0.08 & 0.045 & 0.29 & 0.000 & 0.02 & 0.617 & 0.03 & 0.829 \\
\hline$\Delta \mathrm{CDS}_{\mathrm{t}-2}$ & 0.04 & 0.281 & 0.16 & 0.000 & 0.05 & 0.288 & 0.20 & 0.412 \\
\hline$\Delta \mathrm{CDS}_{\mathrm{t}-3}$ & -0.01 & 0.731 & 0.12 & 0.000 & -0.03 & 0.512 & -0.13 & 0.231 \\
\hline$\Delta \mathrm{CDS}_{\mathrm{t}-4}$ & -0.03 & 0.321 & 0.09 & 0.008 & 0.00 & 0.908 & -0.11 & 0.273 \\
\hline$\Delta \mathrm{BCS}_{\mathrm{t}-1}$ & 0.01 & 0.251 & -0.49 & 0.000 & 0.05 & 0.114 & -0.05 & 0.211 \\
\hline$\Delta \mathrm{BCS}_{\mathrm{t}-2}$ & 0.00 & 0.807 & -0.20 & 0.000 & 0.06 & 0.056 & 0.01 & 0.829 \\
\hline$\Delta \mathrm{BCS}_{\mathrm{t}-3}$ & -0.01 & 0.219 & -0.11 & 0.000 & 0.02 & 0.347 & -0.06 & 0.125 \\
\hline$\Delta \mathrm{BCS}_{\mathrm{t}-4}$ & -0.01 & 0.205 & -0.02 & 0.301 & 0.01 & 0.482 & -0.04 & 0.255 \\
\hline$\Delta \mathrm{EIS}_{\mathrm{t}-1}$ & 0.01 & 0.109 & 0.01 & 0.301 & 0.03 & 0.097 & -0.01 & 0.757 \\
\hline$\Delta \mathrm{EIS}_{\mathrm{t}-2}$ & 0.01 & 0.289 & 0.01 & 0.219 & 0.05 & 0.005 & 0.07 & 0.300 \\
\hline$\Delta \mathrm{EIS}_{\mathrm{t}-3}$ & 0.01 & 0.416 & 0.01 & 0.213 & 0.06 & 0.039 & -0.03 & 0.477 \\
\hline$\Delta \mathrm{EIS}_{\mathrm{t}-4}$ & 0.00 & 0.931 & 0.00 & 0.596 & 0.01 & 0.508 & 0.01 & 0.735 \\
\hline$\Delta \mathrm{OIS}_{\mathrm{t}-1}$ & 0.00 & 0.150 & 0.00 & 0.779 & 0.00 & 0.480 & 0.09 & 0.363 \\
\hline$\Delta \mathrm{OIS}_{\mathrm{t}-2}$ & -0.00 & 0.097 & 0.00 & 0.191 & 0.00 & 0.402 & -0.31 & 0.178 \\
\hline$\Delta \mathrm{OIS}_{\mathrm{t}-3}$ & 0.00 & 0.204 & 0.00 & 0.143 & 0.00 & 0.494 & 0.05 & 0.416 \\
\hline$\Delta \mathrm{OIS}_{\mathrm{t}-4}$ & 0.00 & 0.641 & 0.00 & 0.007 & 0.00 & 0.528 & -0.04 & 0.451 \\
\hline Const. & 0.04 & 0.758 & -0.15 & 0.198 & -0.07 & 0.676 & -0.66 & 0.216 \\
\hline Obs. & 17088 & & 17088 & & 17088 & & 17088 & \\
\hline $\mathrm{R}^{2}$ & 0.018 & & 0.205 & & 0.015 & & 0.223 & \\
\hline
\end{tabular}




\section{Table 5. Granger causality test from firm-specific VAR}

This table reports the number of firms for which we can reject the null hypothesis at the $1 \%$ level that lags 1 to 4 for a particular market have no explanatory power. We perform the test after estimating firm-specific VARs on daily changes in credit default swap spreads (CDS), bond credit spreads (BCS), equity implied spreads (EIS) and option implied spreads (OIS) over the pre-crisis period (January 2006 - July 2007), the sub-prime crisis (August 2007 - July 2009) and the sovereign crisis period (August 2009 - December 2012), as in equations (1) (4).

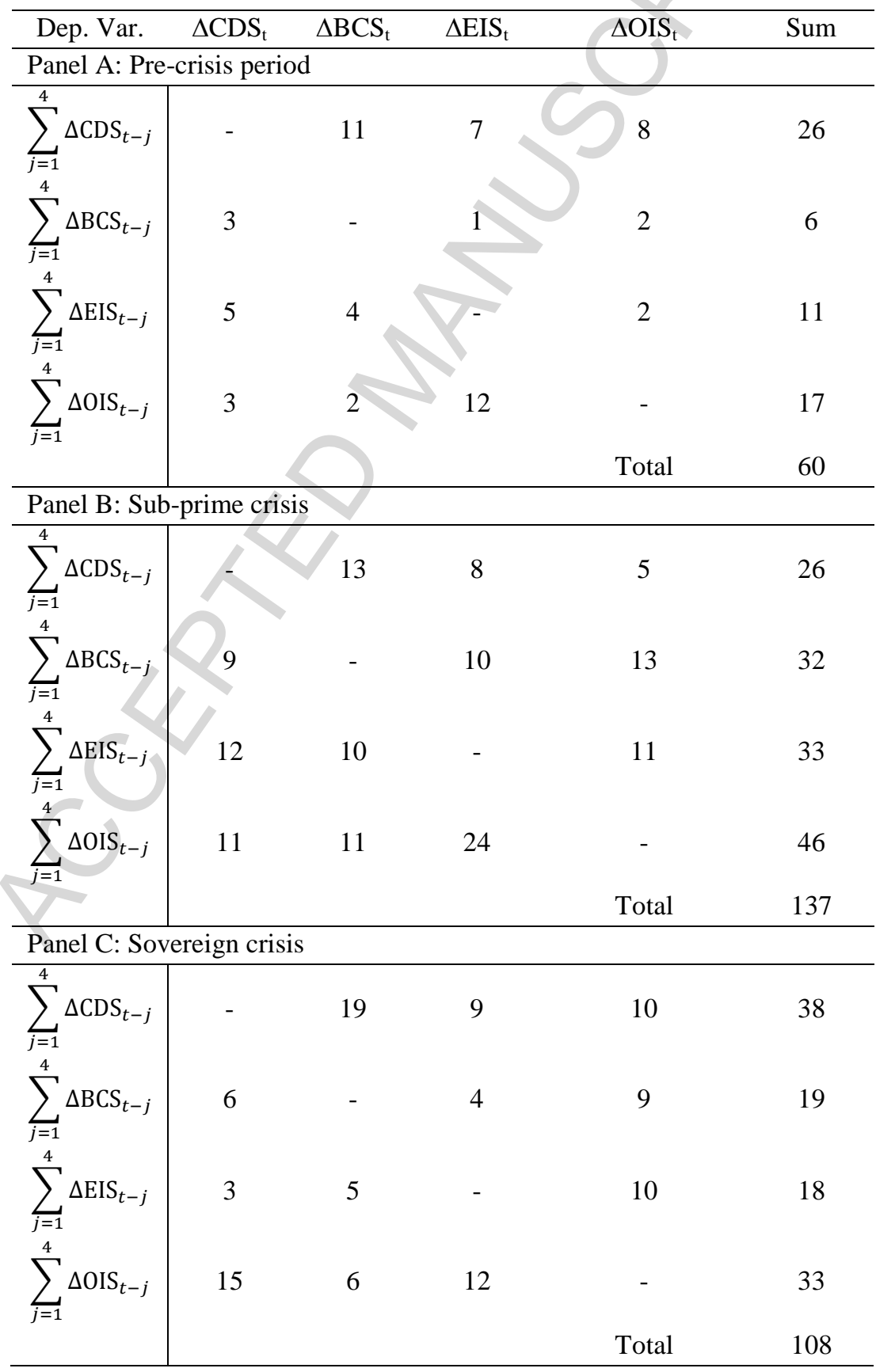




\section{Table 6. Aggregate price discovery analysis: VECM results}

This table reports results obtained from the estimation of a VECM fixed-effect panel regression on daily changes in credit spreads from the credit default swap market (CDS), the bond market (BCS), the equity market (EIS) and the option market (OIS), based on equations (5) - (11). $\lambda_{\mathrm{ji}}$ are the error correction terms. Regressions are estimated on a sample of 20 firms over three different periods, which include a pre-crisis period (January 2006 - July 2007), the sub-prime crisis period (August 2007 - July 2009) and the sovereign crisis period (August 2009 - December 2012). P-values less than 5\% are indicated in bold.

\begin{tabular}{|c|c|c|c|c|c|c|c|c|}
\hline \multirow{2}{*}{ Dep.Var. } & \multicolumn{2}{|c|}{$\Delta \mathrm{CDS}_{\mathrm{t}}$} & \multicolumn{2}{|c|}{$\Delta \mathrm{BCS}_{\mathrm{t}}$} & \multicolumn{2}{|c|}{$\Delta \mathrm{EIS}_{\mathrm{t}}$} & \multicolumn{2}{|c|}{$\Delta \mathrm{OIS}_{\mathrm{t}}$} \\
\hline & Coeff. & p-val. & Coeff. & $p$-val. & Coeff. & $p$-val. & Coeff. & $p$-val. \\
\hline \multicolumn{9}{|c|}{ Panel A: Pre-crisis period } \\
\hline$\lambda_{\mathrm{j} 1}$ & -0.01 & 0.554 & 0.05 & 0.000 & 0.03 & 0.049 & 0.05 & 0.006 \\
\hline$\lambda_{\mathrm{j} 2}$ & 0.01 & 0.813 & -0.14 & 0.000 & -0.03 & 0.324 & -0.06 & 0.089 \\
\hline$\lambda_{\mathrm{j} 3}$ & 0.00 & 0.407 & 0.01 & 0.000 & -0.01 & 0.055 & 0.03 & 0.002 \\
\hline \multicolumn{9}{|c|}{ Panel B: Sub-prime crisis } \\
\hline$\lambda_{\mathrm{j} 1}$ & -0.06 & 0.193 & -0.00 & 0.858 & -0.00 & 0.792 & -0.02 & 0.001 \\
\hline$\lambda_{\mathrm{j} 2}$ & 0.05 & 0.272 & -0.04 & 0.005 & -0.01 & 0.709 & 0.12 & 0.016 \\
\hline$\lambda_{\mathrm{j} 3}$ & 0.00 & 0.154 & -0.00 & 0.924 & -0.03 & 0.035 & 0.01 & 0.523 \\
\hline \multicolumn{9}{|c|}{ Panel C: Sovereign crisis } \\
\hline$\lambda_{\mathrm{j} 1}$ & -0.01 & 0.032 & 0.01 & 0.017 & -0.00 & 0.294 & 0.11 & 0.636 \\
\hline$\lambda_{\mathrm{j} 2}$ & -0.01 & 0.041 & -0.03 & 0.000 & 0.01 & 0.111 & 0.12 & 0.137 \\
\hline$\lambda_{\mathrm{j} 3}$ & 0.00 & 0.000 & 0.01 & 0.000 & -0.00 & 0.105 & 0.05 & 0.275 \\
\hline
\end{tabular}




\section{Table 7. Firm-specific price discovery analysis: VECM results}

This table reports the median coefficients of the error correction terms $\left(\lambda_{\mathrm{ji}}\right)$ estimated from the individual VECMs of daily changes in credit default swap spreads (CDS), bond credit spreads (BCS), equity implied spreads (EIS) and option implied spreads (OIS) over the three sub-periods (Panel A), estimated with equations (5) - (11). In parentheses we indicate the absolute frequency of firms for which the error correction terms are significantly different from zero at the $1 \%$ level and with correct sign. Panel B shows the mean value of the Gonzalo-Granger (GG) measure estimated as in Gonzalo and Granger (1995) across the 20 firms which are cointegrated over the whole sample period.

Panel A: Error correction coefficients and their significance

\begin{tabular}{l|l|cccccc}
\hline \multicolumn{2}{c}{} & \multicolumn{2}{c}{ CSD and Option markets } & \multicolumn{2}{c}{ Bonds and Option markets } & \multicolumn{2}{c}{ Equity and Option markets } \\
\cline { 3 - 8 } \multicolumn{2}{c}{} & Median $\lambda_{11}$ & Median $\lambda_{41}$ & Median $\lambda_{22}$ & Median $\lambda_{42}$ & Median $\lambda_{33}$ & Median $\lambda_{43}$ \\
\hline \multirow{3}{*}{ Sample } & Pre-crisis period & $-0.01(4)$ & $0.01(3)$ & $-0.08(16)$ & $0.00(0)$ & $-0.01(5)$ & $0.04(11)$ \\
& Sub-prime crisis & $-0.05(13)$ & $-0.14(0)$ & $-0.07(15)$ & $0.16(7)$ & $-0.05(18)$ & $0.02(3)$ \\
& Sovereign crisis & $-0.02(8)$ & $-0.01(2)$ & $-0.03(18)$ & $0.00(0)$ & $-0.02(12)$ & $0.10(16)$ \\
\hline
\end{tabular}

Panel B: Gonzalo-Granger measure of price discovery

\begin{tabular}{l|l|cccc}
\hline \multicolumn{2}{l}{ Sample } & CDSs & Bonds & Equities & Options \\
& Pre-crisis period & 0.40 & 0.10 & 0.42 & 0.25 \\
& Sub-prime crisis & 0.38 & 0.42 & 0.16 & 0.25 \\
& Sovereign crisis & 0.59 & 0.06 & 0.49 & 0.14 \\
\hline
\end{tabular}




\section{Table 8. Firm-specific price discovery analysis: VECM results by region}

This table reports the median coefficients of the error correction terms $\left(\lambda_{\mathrm{ji}}\right)$ estimated from the individual VECMs of daily changes in credit default swap spreads (CDS), bond credit spreads (BCS), equity implied spreads (EIS) and option implied spreads (OIS) over the three sub-periods (Panel A for the US sample and Panel $\mathrm{C}$ for the European sample), estimated with equations (5) - (11). In parentheses we indicate the absolute frequency of firms for which the error correction terms are significantly different from zero at the $1 \%$ level and with correct sign. Panel B, for the US sample, and Panel D, for the European sample, show the mean value of the Gonzalo-Granger (GG) measure estimated as in Gonzalo and Granger (1995) across the firms which are cointegrated over the whole sample period for each region. Results are shown separately for the US and European samples.

\section{US Sample}

Panel A: Error correction coefficients and their significance

\begin{tabular}{|c|c|c|c|c|c|c|}
\hline & CSD and Option markets & \multicolumn{2}{|c|}{ Bonds and Option markets } & \multicolumn{2}{|c|}{ Equity and Option markets } \\
\hline & & Median $\lambda_{11} \quad$ Median $\lambda_{41}$ & Median $\lambda_{22}$ & Median $\lambda_{42}$ & Median $\lambda_{33}$ & Median $\lambda_{43}$ \\
\hline \multirow[t]{3}{*}{ Sample } & Pre-crisis period & $0.01(2)$ & $-0.20(10)$ & $0.00(0)$ & $-0.02(3)$ & $0.08(6)$ \\
\hline & Sub-prime crisis & $-0.06(7) \quad-0.30(0)$ & $-0.21(9)$ & $0.14(2)$ & $-0.06(9)$ & $0.02(2)$ \\
\hline & Sovereign crisis & $-0.02(4) \quad-0.01(2)$ & $-0.15(9)$ & $0.00(0)$ & $-0.01(5)$ & $0.10(8)$ \\
\hline \multicolumn{7}{|c|}{ Panel B: Gonzalo-Granger measure of price discovery } \\
\hline & & CDSs & Bonds & Equities & & Options \\
\hline \multirow[t]{3}{*}{ Sample } & Pre-crisis period & 0.42 & 0.09 & 0.44 & & 0.19 \\
\hline & Sub-prime crisis & 0.57 & 0.19 & 0.19 & & 0.27 \\
\hline & Sovereign crisis & 0.39 & 0.04 & 0.55 & & 0.16 \\
\hline
\end{tabular}

European Sample

Panel C: Error correction coefficients and their significance

\begin{tabular}{|c|c|c|c|c|c|c|c|}
\hline & & \multicolumn{2}{|c|}{ CSD and Option markets } & \multicolumn{2}{|c|}{ Bonds and Option markets } & \multicolumn{2}{|c|}{ Equity and Option markets } \\
\hline & & Median $\lambda_{11}$ & Median $\lambda_{41}$ & Median $\lambda_{22}$ & Median $\lambda_{42}$ & Median $\lambda_{33}$ & Median $\lambda_{43}$ \\
\hline \multirow[t]{3}{*}{ Sample } & Pre-crisis period & $-0.02(2)$ & $0.01(1)$ & $-0.03(6)$ & $0.00(0)$ & $-0.01(2)$ & $0.02(5)$ \\
\hline & Sub-prime crisis & $-0.04(6)$ & $-0.01(0)$ & $-0.03(6)$ & $0.20(5)$ & $-0.04(9)$ & $0.02(1)$ \\
\hline & Sovereign crisis & $-0.02(4)$ & $-0.01(0)$ & $-0.02(9)$ & $0.01(0)$ & $-0.02(7)$ & $0.10(8)$ \\
\hline \multicolumn{8}{|c|}{ Panel D: Gonzalo-Granger measure of price discovery } \\
\hline & & \multicolumn{2}{|c|}{ CDSs } & Bonds & Equities & \multicolumn{2}{|r|}{ Options } \\
\hline \multirow[t]{3}{*}{ Sample } & Pre-crisis period & \multicolumn{2}{|l|}{0.40} & 0.10 & 0.40 & \multicolumn{2}{|r|}{0.32} \\
\hline & Sub-prime crisis & \multicolumn{2}{|l|}{0.20} & 0.65 & 0.13 & \multicolumn{2}{|r|}{0.20} \\
\hline & Sovereign crisis & \multicolumn{2}{|l|}{0.80} & 0.07 & 0.42 & & 0.12 \\
\hline
\end{tabular}




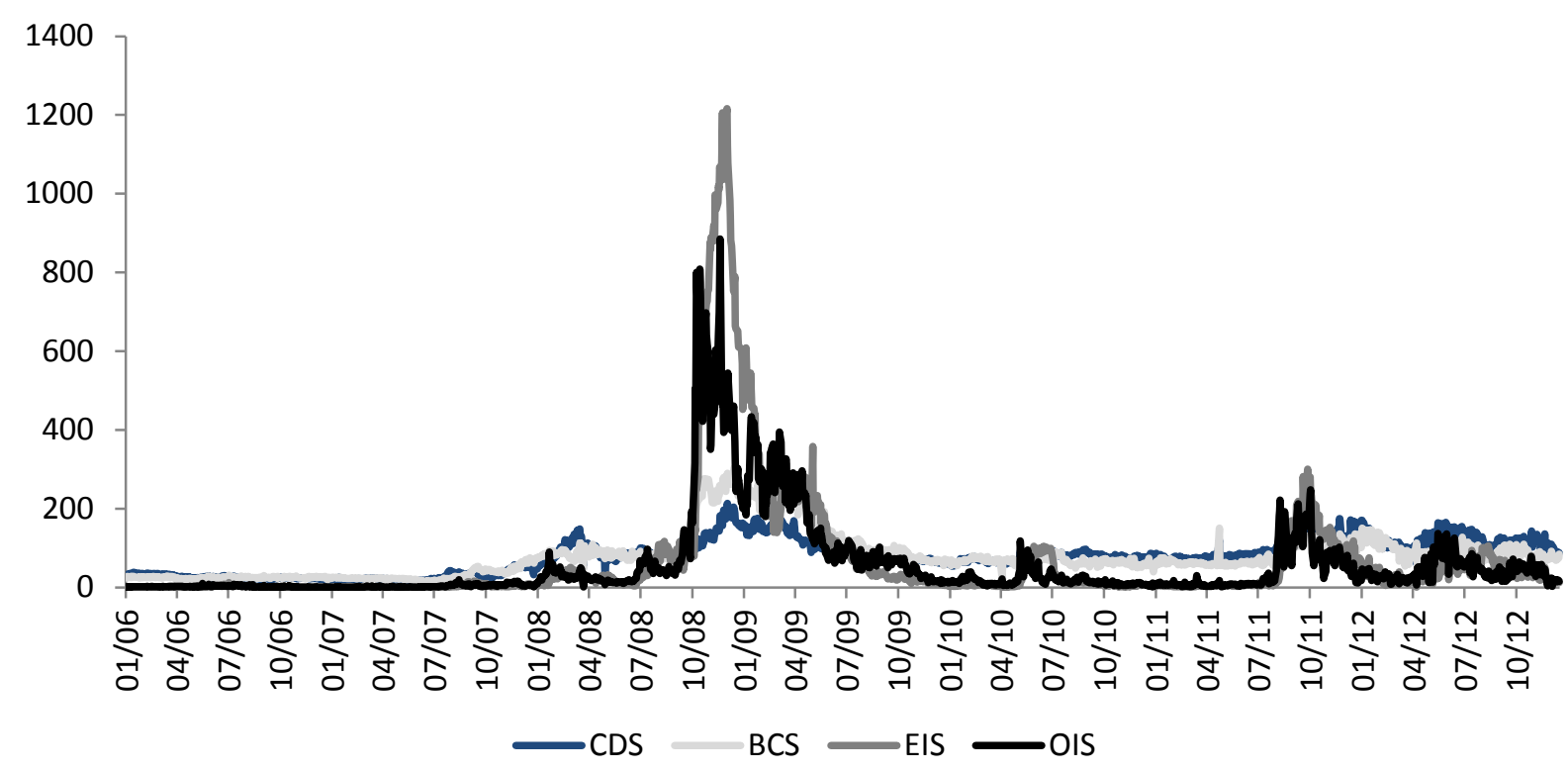

Figure 1. Time series of credit spreads

This figure shows time series of daily cross sectional median spreads obtained from the credit default swap market (CDS), the bond market (BCS), the equity market (EIS) and the option market (OIS) during the period 2006-2012. 


\section{Price discovery of credit spreads in tranquil and crisis periods}

Highlights:

- We study price discovery in credit spreads derived from four markets

- We perform both a panel and a firm by firm analysis

- Option implied spreads lead price discovery in crisis periods in the short term

- The option market no longer has a prominent role in long term price discovery. 